\title{
Assessment of specimen fixation in a surgical pathology service
}

\author{
R D Start, S S Cross, J H F Smith
}

\begin{abstract}
The quality of specimen fixation was examined within a routine diagnostic histopathology service. For each specimen the adequacy of fixation was assessed and the transit time between operating theatre and the laboratory was measured. Preliminary fixation was found to be inadequate in $25 \%$ of specimens and some form of manipulation to assist fixation was required in $36 \%$ of specimens. The mean transit time was 22 (SD 10.7) hours. Specimen fixation and transport are additional factors to consider in quality assurance of histopathology.
\end{abstract}

Prompt, adequate fixation of tissue is essential to preserve morphological features for histopathological diagnosis; delay reduces the number of observable mitotic figures ${ }^{12}$ and may affect the immunoreactivity of tissue antigens. ${ }^{34}$ Biopsy material may be placed in fixative at the time of removal or sent to the histopathology laboratory in an unfixed state for the harvest of fresh tissue before fixation. Specimens may be immersed whole or sliced to facilitate the penetration of fixative. This study examines the quality and efficiency of specimen fixation within one hospital.

\section{Methods}

The date and time of excision of each specimen was recorded on the histopathology request form by the participating surgeons. The date and time of arrival of each specimen in the pathology laboratory was recorded and the quality of fixation was assessed jointly by a pathologist and a senior MLSO. The variables considered for each specimen were the presence of an appropriate fixative with an optimal ratio of volume of the specimen to the volume of fixative present and the correct size of specimen container.

Breast specimens, in which a relatively small lesion is often situated within a large mass of tissue, were analysed further with measurement of the distance from the tumour edge to the nearest resection margin. The final histological sections from all specimens were examined for any effects related to the quality of fixation.

The study was limited to a single surgical firm to maximise compliance and confidentiality. Portering and theatre staff were not informed of the study. The study was conducted over 10 weeks during which 132 specimens were received; 12 specimens were excluded due to incomplete information.

The histopathology laboratory is situated in a separate building approximately $500 \mathrm{~m}$ from the main theatre block and $150 \mathrm{~m}$ from the minor surgery clinic. Routine deliveries of specimens arrive each morning on Monday to Saturday, with an additional delivery on Friday afternoon. Specimens from the nearby minor surgery clinic are delivered each afternoon.

\section{Results}

The results are summarised in tables $1-2$. The mean transit time between the operating theatres and the laboratory was 22.0 hours, but there was considerable variation with a standard deviation (SD) of 10.7 hours. Of the 27 specimens which were delivered within six hours of removal, $17(63 \%)$ came from the nearby minor surgery clinic. Specimens removed during emergency surgery at weekends represented $40 \%(n=12)$ of specimens with transit times of 24 hours or longer $(n=30)$. The mean transit time for breast specimens $(n=28)$ was $22 \cdot 7$ hours (SD 6.9). The mean distance between tumour edge and nearest resection margin was $8.7 \mathrm{~mm}$ (SD 8.4) for lumpectomy specimens $(n=21)$ and $18 \cdot 7$ mm (SD 9.4) for mastectomy specimens $(\mathrm{n}=7)$.

Preliminary fixation was found to be inadequate in $25 \%$ of specimens $(n=30)$ for the reasons given in table $2 ; 36 \%$ of specimens $(n=42)$ required manipulation by slicing or partial dissection to assist fixation. Clinically important autolysis with poor cellular detail reduced the quality of final sections from eight specimens (including two breast specimens). This did not prevent diagnosis, although the grade of tumour in breast specimens may have been affected. ${ }^{2}$ All eight specimens were received in an insufficient volume of fixative.

\section{Discussion}

Previous studies have audited the packaging of pathological specimens ${ }^{5}$ and the turnround times for specimens, ${ }^{6}$ but we are not aware of any published studies on the adequacy of specimen fixation. Our results show inadequate preliminary fixation in $25 \%$ of specimens and a mean transit time between the place of removal and the pathology laboratory of $22 \cdot 0$ hours. This combination could result in the inadequate fixation of specimens with consequential problems for accurate histopathological assessment. ${ }^{2}$ 
Table 1 Distribution of specimen transit times *

\begin{tabular}{lllllllll}
\hline \multicolumn{10}{c}{ Transit time (hours) } \\
\cline { 2 - 9 } & $0-6$ & $6-12$ & $12-18$ & $18-24$ & $24-36$ & $36-48$ & $>48$ & Total \\
\hline Number of specimens & $27(23)$ & $5(4)$ & $16(13)$ & $42(35)$ & $18(15)$ & $10(8)$ & $2(2)$ & $120(100)$ \\
\hline${ }^{\star}$ Figures in parentheses are percentage of total specimens
\end{tabular}

The usual fixative used in our laboratory is $4 \%$ formaldehyde solution which, in common with most fixatives, penetrates tissue slowly at a rate of about $4 \mathrm{~mm}$ in 24 hours. ${ }^{7}$ This slow penetration means that most of the breast tumours within the lumpectomy and mastectomy specimens in this study will not have been adequately fixed unless they were sliced at the time of removal at surgery. This practice is actively discouraged by most pathologists because the distortion and shrinkage in specimens, which are sliced before any formal pathological assessment, can complicate the subsequent interpretation of the specimen. ${ }^{8} \mathrm{~A}$ fixation delay of just six hours can produce changes in the grading of breast carcinomas as a result of decreased mitotic counts ${ }^{2}$ : an efficient system of specimen fixation is essential.

Reorganisation of the specimen delivery service could reduce the transit time of most specimens; the replacement of the morning delivery by an afternoon service would have avoided an overnight delay (16 hours) for 57 $(48 \%)$ specimens removed after the daily specimen collection from theatre. This change would have produced a reciprocal increase in the transit times of only $13(11 \%)$ specimens. A shorter transit time would allow specimens, which might require slicing or opening to ensure adequate fixation, to be assessed earlier.

Rapid specimen transfer is particularly important for those laboratories in which large specimens are received without fixative. Any delay in transit will permit considerable autolysis unless the specimen is adequately refrigerated and alternative arrangements must be available for specimens removed over weekends. ${ }^{8}$ This type of system is not practical in our hospital because of the distance between the laboratory and theatre complex.

Table 2 Variables of preliminary specimen fixation

\begin{tabular}{lc}
\hline Fixation & $\begin{array}{c}\text { Number of } \\
\text { Specimens }\end{array}$ \\
\hline $\begin{array}{l}\text { Appropriate fixation } \\
\text { Inappropriate absence of fixative }\end{array}$ & $90(75 \%)$ \\
$\begin{array}{l}\text { Inappropriate type of fixative } \\
\begin{array}{l}\text { Insufficient volume of fixative } \\
\text { with correct size of container }\end{array}\end{array}$ & $3(1 \%)$ \\
$\begin{array}{l}\text { Insufficient volume of fixative } \\
\text { with incorrect size of container }\end{array}$ & $4(3 \%)$ \\
Total & $120(100 \%)$ \\
\hline
\end{tabular}

The large proportion of specimens which were received inadequately fixed $(30 \%)$ is indicative of the failure to understand the requirements for adequate fixation. Good liaison between pathologists, clinicians, theatre and laboratory staff is essential if the most appropriate fixative is to be selected and used correctly. The quality of fixation could be greatly improved by greater education of all staff in association with a shorter transit time which would allow pathology staff to optimise fixation conditions. Some antigens have reduced immunoreactivity with prolonged periods of fixation, ${ }^{34}$ and a shorter transit time would allow specimens to be processed after a fixation time which would give maximum immunoreactivity. Laboratories must be aware of the possible conflict between the requirements of routine histology and immunohistochemistry. Other investigations require access to fresh unfixed tissue ${ }^{8}$ and any specimens requiring special attention should be identified in advance and arrangements made for their collection.

The efficiency and quality of fixation is another variable which can be included in laboratory performance indicators and should be included in the criteria for laboratory accreditation. $^{910}$

We thank Professor K Rogers and his clinical staff for providing the specimens and Mr M Kay and his MLSO staff for their technical assistance.

1 Cross SS, Start RD, Smith JHF. Does delay in fixation affect the number of mitotic figures in processed tissue? $\mathcal{F}$ Clin Pathol 1990;43:597-9.

2 Start RD, Flynn MS, Cross SS, Rogers K, Smith JHF. Is the grading of breast carcinoma affected by a delay in fixation? Virchows Arch (Pathol Anat) 1991;419:475-7.

3 Leong AS, Gilham PN. The effects of progressive formaldehyde fixation on the preservation of tissue antigens. Pathology 1989;21:266-8.

4 Hall PA, Levison DA, Woods AL, et al. Proliferating cell nuclear antigen (PCNA) immunolocalization in paraffin sections: an index of cell proliferation with evidence of deregulated expression in some neoplasms. F Pathol 1990;162:285-94.

5 Garner P, Masterton RG. Specimen transport audit. $f$ Clin Pathol 1990;43:712-3.

6 Rogers S, Bywater MJ, Reeves DS. Audit of turn-around times in a microbiology laboratory. $\mathcal{f}$ Clin Pathol $1991 ; 44: 257-8$

7 Medawar PB. The rate of penetration of fixatives. $f R$ Microsc Soc 1942;61:46-57.

8 Kennedy A. Basic techniques in diagnostic histopathology. Edinburgh: Churchill Livingstone, 1977:1-11.

9 The College Accreditation Steering Committee. Royal College of Pathologists' United Kingdom pilot study of laboratory accreditation. $\mathcal{f}$ Clin Pathol 1990;43:89-91.

10 The College Accreditation Steering Committee. Royal College of Pathologists' accreditation pilot study: a year later. $\mathcal{f}$ Clin Pathol 1991;44:172-3. 